\title{
PENGARUH PROMOSI PENJUALAN, DAYA TARIK IKLAN INTERNET, DAN KUALITAS WEBSITE TERHADAP PEMBELIAN IMPULSIF
}

\author{
Maria Fernanda \\ Program Studi Magister Manajemen Universitas Tarumanagara \\ fernanda93maria@gmail.com
}

\begin{abstract}
This goal of this study is to find out whether sales promotion, internet advertising, and website quality influence impulsive buying. This study was conducted using descriptive study approach. Subject of this study were consumers in Jakarta who have made purchase during last 6 months. Data in this study was obtained from questionnaire which distributed to 150 respondents. Method used in sampling was non probability sampling with convenience sampling. The collected data was tested using multiple regression analysis method in SPSS. The result of this study showed, each variables : sales promotion, internet advertising, and website quality have significant and positive effect on impulse buying.
\end{abstract}

Abstrak : Penelitian ini bertujuan untuk mengetahui apakah promosi penjualan, daya tarik iklan internet, dan kualitas website berpengaruh terhadap pembelian impulsif. Jenis penelitian ini adalah penelitian desktiptif. Subjek dalam penelitian ini adalah masyarakat Jakarta yang pernah melakukan pembelian dalam 6 bulan terakhir. Data yang diperoleh dari kuesioner yang disebarkan ke sebanyak 150 responden. Metode pengambilan sampel dilakukan dengan metode non-probability sampling teknik convenience sampling. Analisis data dilakukan dengan menggunakan analisis regresi linear berganda yang diolah dengan bantuan software SPSS. Hasil penelitian menunjukkan bahwa masing-masing variabel : promosi penjualan, daya tarik iklan internet, dan kualitas website berpengaruh secara positif dan signifikan terhadap pembelian impulsif.

Keywords : Sales Promotion, Internet Advertising, Website Quality, Impulsive Buying

\section{PENDAHULUAN}

Pesatnya perkembangan internet turut merubah pola hidup masyarakat, salah satunya dalam hal transaksi jual beli. Kegemaran masyarakat berbelanja online menjadi pemicu maraknya perusahaan e-commerce di Indonesia. Maraknya e-commerce tersebut membuat konsumen memiliki banyak alternatif tempat untuk berbelanja. Maka dari itu perusahaan perlu berinisiatif dan berinovasi agar dapat tetap mempertahankan pangsa pasar dan menarik konsumen baru. Perusahaan perlu mempelajari karakteristik masyarakat Indonesia yang unik. Sebagaimana diungkapkan oleh Cintananda (2018), konsumen Indonesia cenderung masih belum memiliki perencanaan yang baik. Itulah sebabnya tingkat pembelian impulsif di Indonesia masih tinggi. Dalam melakukan pembelian online maupun offline, masyarakat Indonesia sering menjadi impulse buyer.

Sejalan dengan hal tersebut, menurut Dyatmika (2015), sebagian besar konsumen Indonesia memiliki karakter unplanned. Mereka biasanya suka bertindak last minute. Jika berbelanja, mereka sering menjadi impulse buyer. Pembelian impulsif (Impulse buying) atau biasa disebut juga unplanned purchase, adalah perilaku orang dimana orang tersebut tidak merencanakan sesuatu dalam berbelanja.

Penelitian yang dilakukan Yarahmadi (2016) menyimpulkan bahwa promosi penjualan berpengaruh signifikan terhadap pembelian impuls. Promosi penjualan merupakan salah satu upaya perusahaan agar konsumen mencoba suatu barang atau jasa. Pemberian insentif seperti diskon waktu terbatas, akan memberikan nilai tambah dan merangsang konsumen untuk melakukan pembelian yang tidak direncanakan sebelumnya. 
Ariani (2016) menyebutkan bahwa segala bentuk iklan memang difungsikan untuk menarik minat para konsumen. Akan tetapi daya tarik iklan pada online shop memiliki tampilan yang berbeda dibandingkan dengan media televisi. Televisi menggunakan iklan berbentuk video dengan durasi sekitar 3 menit. Sedangkan online shop menggunakan gambar untuk menampilkan produk yang dijual. Beberapa penelitian sebelumnya menunjukkan bahwa iklan yang menarik dan berhasil mengikat emosi konsumen dapat meningkatkan pembelian impulsif. Penelitian yang dilakukan Maulana (2016) menunjukkan bahwa daya tarik iklan internet berpengaruh positif dan signifikan terhadap pembelian impulsif.

Irshadi (2016) menyebutkan, dalam bidang e-commerce, salah satu faktor pendukungnya adalah website. Dengan memiliki website yang berkualitas maka akan didapat keunggulan bersaing. Margaret (2016) dari penelitiannya mendapatkan kesimpulan bahwa kualitas website berpengaruh positif terhadap pembelian impulsif online.

Dari hasil-hasil penelitian terdahulu yang dikemukakan diatas, ditemukan bahwa terdapat pengaruh antara variabel-variabel independen yang diteliti terhadap pembelian impulsif.

\section{TELAAH KEPUSTAKAAN \\ Pembelian Impulsif}

Kharis (2011) menyebutkan bahwa impulse buying atau biasa disebut juga unplanned purchase adalah perilaku orang dimana orang tersebut tidak merencanakan sesuatu dalam berbelanja. Kharis juga memaparkan, dalam pembelian impulsif ada karakteristik tertentu yaitu spontanitas; kekuatan, kompulsi, dan intensitas; kegairahan dan stimulasi; dan ketidakpedulian akan akibat.

\section{Promosi Penjualan}

Kotler dan Armstrong (2012:505) mengatakan bahwa "Sales Promotion consists of short-term incentives to encourage purchase or sales of product or service." Dapat diartikan bahwa promosi penjualan berkaitan dengan insentif jangka pendek untuk mendorong pembelian atau penjualan dari suatu produk atau jasa. Insentif ini berkaitan dengan imbalan, apakah itu berkaitan dengan pengembalian uang dalam bentuk diskon, jaminan atau dapat berupa sampel produk dan sebagainya.

\section{Daya Tarik Iklan Internet}

Maulana (2016) daya tarik iklan internet yaitu bentuk konten komersial di internet yang didesain oleh pebisnis untuk menginformasikan kepada konsumen tentang produk atau jasa. Internet advertising adalah komunikasi nonpersonal yang bersifat persuasif.

\section{Kualitas Website}

Gregg dan Walczak (2010:5), mendefinisikan kualitas website sebagai 'the attributes of a website that contribute to its usefulness to consumers'. Dapat disimpulkan bahwa kualitas website adalah atribut dari sebuah website yang berkontribusi terhadap kegunaannya kepada konsumen.

\section{Kaitan antar Variabel}

1. Pengaruh promosi penjualan terhadap pembelian impulsif

Yarahmadi (2011) pada penelitiannya menemukan bahwa promosi penjualan dalam bentuk free product dan discount berpengaruh signifikan dan positif terhadap penjualan impulsif. Penelitian yang dilakukan oleh Sugianto (2016) juga menemukan bahwa promosi penjualan dalam bentuk pemberian diskon dan hadiah, berpengaruh positif dan signifikan terhadap perilaku pembelian impulsif. Demikian juga penelitian yang dilakukan oleh Kharis (2011) dan Cintananda (2018), juga menunjukkan hasil yang sama, yakni promosi penjualan memiliki pengaruh positif dan signifikan terhadap perilaku pembelian impulsif. Berdasarkan uraian tersebut, hipotesis penelitian (H1) adalah:

H1 : Terdapat pengaruh positif pada promosi penjualan terhadap pembelian impulsif 
2. Pengaruh daya tarik iklan internet terhadap pembelian impulsif

Beberapa penelitian sebelumnya menunjukkan bahwa iklan yang menarik dan berhasil mengikat emosi konsumen dapat meningkatkan pembelian impulsif. Penelitian yang dilakukan Maulana (2016) menunjukkan bahwa daya tarik iklan internet berpengaruh positif dan signifikan terhadap pembelian impulsif. Sejalan dengan hal tersebut, penelitian yang dilakukan Ariani (2016) juga memberikan hasil bahwa daya tarik iklan online shop berpengaruh terhadap pembelian impulsif. Berdasarkan uraian tersebut, hipotesis penelitian (H2) adalah:

$\mathrm{H} 2$ : Terdapat pengaruh positif daya tarik iklan internet terhadap pembelian impulsif

3. Pengaruh kualitas website terhadap pembelian impulsif

Dalam hasil penelitiannya, Margaret (2016) menyimpulkan bahwa kualitas website berpengaruh positif terhadap pembelian impulsif online. Berdasarkan penelitian Cintananda (2018), juga didapatkan hasil bahwa ada pengaruh signifikan dan positif antara kualitas website terhadap perilaku pembelian impulsif. Selain itu, penelitian yang dilakukan oleh Sugianto (2016) mendapatkan hasil bahwa variabel website quality, berpengaruh signifikan terhadap impulse buying pada Zalora. Berdasarkan uraian tersebut, hipotesis penelitian (H3) adalah:

H3 : Terdapat pengaruh positif pada kualitas website terhadap pembelian impulsif

\section{METODOLOGI PENELITIAN}

Jenis penelitian yang dilakukan adalah penelitian deskriptif dengan pendekatan cross sectional. Menurut Sugiyono (2005) cross sectional yaitu pengamatan hanya dilakukan sekali sesuai dengan waktu yang ditentukan oleh peneliti dengan melihat adanya hubungan antara variabel dependen dan independen. Periode penelitian dilakukan dari bulan Januari 2019 sampai dengan Maret 2019.

Kuesioner yang disebarkan dengan google form digunakan untuk mengumpulkan data, skala pengukuran variabel penelitian dilakukan dengan skala likert yang terdiri dari 5 pilihan jawaban, dimana nilai 1 menunjukkan sangat tidak setuju, hingga nilai 5 menunjukkan sangat setuju. Populasi dalam penelitian ini adalah masyarakat Jakarta yang pernah melakukan pembelian dalam waktu 6 bulan terakhir. Sampel diambil sebanyak 150 responden dengan metode non-probability sampling teknik convenience sampling.

Dapat dilihat pada Tabel 1 jumlah item serta sumber variabel penelitian yang digunakan.

Tabel 1. Variabel dan Pengukuran

\begin{tabular}{|l|c|c|}
\hline \multicolumn{1}{|c|}{ Variabel } & Item & Sumber \\
\hline Variabel independen: & & \\
Promosi Penjualan & 4 & Kotler dan Armstrong (2006) \\
Daya Tarik Iklan Internet & 4 & Maulana (2016) \\
Kuaitas Website & 14 & Bressolles dan Giraud (2007) \\
\hline Variabel dependen: & & \\
Pembelian Impulsif & 8 & Kharis (2011) \\
\hline
\end{tabular}

Analisis regresi linear berganda digunakan untuk mengetahui pengaruh masing-masing variabel independen terhadap variabel dependen. Sebelumnya, dilakukan terlebih dahulu uji validitas, reliabilitas, dan uji asumsi klasik dengan menggunakan taraf signifikansi 0,05 .

\section{HASIL PENELITIAN DAN PEMBAHASAN}

Berdasarkan data yang didapatkan dari 150 responden, dan diketahui bahwa mayoritas responden adalah wanita $(56,7 \%)$, dengan rentang usia di 24-29 tahun (46,0\%), pekerjaan karyawan swasta/negri $(38,7 \%)$, produk yang paling sering dibeli adalah fashion $(31,3 \%)$, dan frekuensi belanja 6 bulan terakhir sebanyak 2-5x $(63,3 \%)$.

Hasil uji validitas menunjukkan bahwa nilai corrected item total correlation seluruh item pada tiap variabel penelitian lebih besar dari $r$ tabel untuk signifikansi 0,05 , yaitu 0,160. 
Maka seluruh item pada tiap variabel penelitian dinyatakan valid. Sementara itu hasil dari uji reliabilitas terhadap seluruh variabel penelitian diperoleh nilai Cronbach's Alpha tiap variabel lebih besar dari 0,600, seluruh variabel penelitian ini dinyatakan reliabel.

\section{Pengujian Hipotesis}

Dapat dilihat pada Tabel 2, variabel promosi penjualan, daya tarik iklan internet, dan kualitas website memiliki nilai signifikansi lebih kecil dari 0,05. Maka disimpulkan hipotesis $\mathrm{H} 1, \mathrm{H} 2$, dan $\mathrm{H} 3$ diterima. Kemudian dari nilai koefisien pada tabel dibawah, dapat dilihat variabel promosi penjualan memiliki pengaruh paling besar terhadap pembelian impulsif dibandingkan variabel daya tarik iklan internet maupun kualitas website.

Tabel 2. Hasil Analisis Regresi

\begin{tabular}{|l|l|c|c|}
\hline \multicolumn{2}{|c|}{ Hipotesis } & Koefisien & Sig. \\
\hline $\mathrm{H}_{1}$ & Promosi penjualan $\rightarrow$ pembelian impulsif & 0,366 & 0,000 \\
\hline $\mathrm{H}_{2}$ & Daya tarik iklan internet $\rightarrow$ pembelian impulsif & 0,356 & 0,000 \\
\hline $\mathrm{H}_{3}$ & Kualitas Website $\rightarrow$ pembelian impulsif & 0,343 & 0,000 \\
\hline
\end{tabular}

Dari hasil pengujian $\mathrm{H}_{1}$, didapatkan hasil penelitian bahwa promosi penjualan memiliki pengaruh positif dan signifikan terhadap pembelian impulsif. Pemberian promosi penjualan berupa insentif jangka pendek seperti potongan harga, cashback, flash sale, dan potongan ongkos pengiriman dapat memberikan rangsangan bagi konsumen untuk melakukan pembelian yang tidak direncanakan sebelumnya ataupun menambahkan jumlah pembelian. Sejalan dengan penelitian yang dilakukan oleh Yarahmadi (2011) dan Sugianto (2016), bahwa promosi penjualan dalam bentuk pemberian diskon dan hadiah, berpengaruh positif dan signifikan terhadap perilaku pembelian impulsif. Selain itu penelitian yang dilakukan oleh Kharis (2011) juga menyimpulkan bahwa pemberian promosi penjualan dapat mendorong pembelian produk dengan segera. Hasil penelitian Cintananda (2018), menyimpulkan bahwa variabel yang paling berpengaruh signifikan terhadap pembelian impulsif adalah promosi penjualan.

Dari hasil pengujian $\mathrm{H}_{2}$, didapatkan hasil penelitian bahwa daya tarik iklan internet memiliki pengaruh positif dan signifikan terhadap pembelian impulsif. Dalam pembelian impulsif banyak dipengaruhi oleh aspek emosional, iklan yang mampu memberikan keterikatan terhadap konsumen secara emosional dapat menimbulkan sensasi kesenangan ketika konsumen melakukan pembelian, perasaan cinta terhadap produk, kenyamanan ketika melakukan pembelian, dan perasaan ingin memiliki produk yang tinggi. Penampilan iklan yang unik dan berbeda, pemberian informasi iklan yang sesuai dan mudah dipahami serta menarik perhatian, juga ditunjukkan dapat meningkatkan pembelian tidak terencana. Sejalan dengan penelitian yang dilakukan oleh Maulana (2016), dimana hasil penelitiannya menunjukkan bahwa daya tarik iklan internet berpengaruh positif dan signifikan terhadap pembelian impulsif online. Selain itu penelitian sejenis yang dilakukan oleh Ariani (2016) juga memberikan hasil bahwa daya tarik iklan online shop berpengaruh terhadap pembelian impulsif

Dari hasil pengujian $\mathrm{H}_{3}$, didapatkan hasil penelitian bahwa kualitas website memiliki pengaruh positif dan signifikan terhadap pembelian impulsif. Website yang dirancang dengan baik akan mengundang konsumen untuk berbelanja di website tersebut. Perlu diperhatikan pula, bahwa dalam belanja online tidak hanya untuk menarik konsumen, tapi suatu website yang berkualitas perlu juga memperhatikan aspek lain seperti ketepatan pemberian informasi, kemudahan penggunaan, keandalan, desain situs, privasi, dan kemudahan interaksi (interaktif). Sejalan dengan penelitian yang dilakukan oleh Margaret (2016), disimpulkan bahwa kualitas website berpengaruh positif terhadap pembelian impulsif online Berdasarkan penelitian serupa yang dilakukan Cintananda (2018), juga didapatkan hasil bahwa ada pengaruh signifikan dan positif antara kualitas website terhadap perilaku pembelian impulsif. Selain itu, penelitian yang dilakukan oleh Sugianto (2016) mendapatkan hasil bahwa variabel website quality, berpengaruh signifikan terhadap impulse buying pada Zalora. 


\section{KESIMPULAN DAN SARAN}

Hasil penelitian menunjukkan bahwa secara parsial promosi penjualan, daya tarik iklan internet, kualitas website berpengaruh positif dan signifikan terhadap pembelian impulsif

Dalam penelitian ini, adanya keterbatasan penulis yaitu pengumpulan data berasal hanya dari masyarakat kota Jakarta dan jumlah sampel yang digunakan sebesar 150. Selain itu, variabel independen yang diteliti terhadap pembelian impulsif hanya variabel promosi penjualan, daya tarik iklan internet, dan kualitas website.

Untuk penelitian selanjutnya, penulis menyarankan agar peneliti dapat menambahkan variabel lain yang dapat mempengaruhi pembelian impulsif di e-commerce. Variabel lain yang dapat ditambahkan seperti pengalaman pembelian sebelumnya, online review, maupun faktor yang lebih memfokuskan pada karakteristik konsumen seperti : shopping lifestyle, situasi ekonomi, dan gaya hidup hedonis. Selain itu penulis juga menyarankan penelitian selanjutnya agar dapat memperluas cakupan wilayah penelitian dengan menambah domisili responden dari kota lainnya di Indonesia dan memperbesar ukuran sampel.

\section{IMPLIKASI MANAJERIAL}

Berdasarkan hasil penelitian, penulis menyampaikan beberapa implikasi penelitian bagi pihak perusahaan. Perusahaan perlu mempertahankan dan meningkatkan pemberian promosi penjualan agar dapat menarik konsumen baru dan meningkatkan jumlah pembelian. Bentuk promosi penjualan yang dapat ditingkatkan adalah pemberian flash sale. Dalam memberikan flash sale kiranya perusahaan dapat mempersiapkan server website agar ketika diakses konsumen saat flash sale tidak mengalami down. Perusahaan juga dapat menambahkan bentuk promosi penjualan yang lebih beragam, seperti memberikan sampel ataupun mengadakan giveaway produk Official Store.

Perusahaan juga perlu memperhatikan kategori produk yang diiklankan di internet, perusahaan kiranya dapat lebih meningkatkan iklan internet untuk kategori produk yang kurang populer atau sedikit peminat. Dalam penelitian ini kategori produk yang jumlah peminatnya paling sedikit, antara lain kategori makanan \& minuman, dan perlengkapan rumah tangga \& dapur. Agar dapat menarik perhatian konsumen, perusahaan perlu membuat iklan dengan visual yang unik Selain itu perusahaan juga perlu memastikan bahwa informasi yang ditampilkan di iklan internet mudah dipahami dan sesuai, untuk mengurangi resiko timbulnya kekecewaan konsumen.

Perusahaan perlu terus menerus meningkatkan kualitas website agar dapat meningkatkan pengalaman yang menyenangkan bagi konsumen dalam berbelanja online. Dalam belanja di $e$ commerce, dimana penjualnya berasal dari banyak pihak, perusahaan perlu tetap memperhatikan dan memastikan keamanan konsumen. Hal ini dapat dilakukan perusahaan dengan meningkatkan pelayanan terhadap komplain yang diajukan dan berperan sebagai mediator yang membantu menengahi ketika terjadi permasalahan antara penjual dan pembeli. Dengan adanya asistensi dari perusahaan, tentunya akan membuat konsumen merasa lebih percaya untuk berbelanja kembali di perusahaan tersebut.

\section{DAFTAR PUSTAKA}

Ariani, Rizka Maulidya Nur Ariani. (2016). Pengaruh Daya Tarik Iklan Online Shop terhadap Pembelian Impulsif (Impulsive Buying) pada Mahasiswi Fakultas Psikologi Universitas Islam Negeri (UIN) Maulana Malik Ibrahim. Malang : Universitas Islam Negri Maulana Malik Ibrahim.

Bressolles, G., Durrieu, F., dan M. Giraud (2007). The Impact of Eletronic Service Quality's Dimensions on Customer Satisfaction and Buying Impulse. Journal of Customer Behaviour, 6(1), 37-56. 
Cintananda, Anggy N.P.P. (2018). Pengaruh Kualitas Website, Electronic Word of Mouth, dan Promosi Penjualan terhadap Pembelian Impulsif pada Shopee. Yogyakarta : Universitas Muhammadiyah Yogyakarta.

Dyatmika, I Gde Made Dharma Tatwa dan Ida Bagus Sudiksa. (2015). Pengaruh Promosi dan Pelayanan Ritel terhadap Pembelian Impulsif di Ramayana Mall Denpasar. E-Jurnal Manajemen Universitas Udayana, 1 (4), 21-38.

Gregg, G. Dawn, dan Steven Walchzak (2010). The Relationship Between Website Quality, Trust and Price Premiums at Online Auctions. Electronic Commerce Research, 1 (10), 1 25.

Irshadi, Fariz dan Ratih Hendayani. (2016). Pengaruh Kualitas Website terhadap Keputusan Pembelian pada Pengunjung Website Mataharimall.com. e-Proceeding of Management, 3 (3), 2822-2827.

Kharis, Ismu Fadli. (2011). Studi Mengenai Impulse Buying dalam Penjualan Online. Jurnal Universitas Diponegoro Semarang.

Kotler, Philip dan Amstrong, Gary. (2006). Prinsip-prinsip Pemasaran, Erlangga, Jakarta

Margaret, Olivia dan MF. Shellyana Junaedi. (2016). Pengaruh Sifat Impulsif dan Kualitas Website terhadap Pembelian Impulsif Online di Lazada. E-Journal UAJY, 1-15.

Maulana, Muamar Fachmi. (2016). Pengaruh Kecanduan Internet, Daya Tarik Iklan Internet, dan Kepemilikan Kartu Kredit terhadap Perilaku Pembelian Impulsif Online. Bandung : Universitas Komputer Indonesia.

Sugianto, Yonita Magdalena Ngurah. (2016). Pengaruh Website Quality, Electronic Word-of Mouth, dan Sales Promotion terhadap Impulse Buying pada Zalora. Jurnal Strategi Pemasaran, 2 (3).

Sugiyono. (2005). Metode Penelitian Kuantitatif Kualitatif dan R\&D. Bandung : Alfabeta

Yarahmadi, Hasti dan Karbasivar Alireza. (2011). Evaluating Effective Factors on Consumer Impulse Buying Behavior. Asian Journal of Business Management Studies, 2 (4), 174181. 